\title{
IS ENGLISH REALLY THE CULPRIT? INVESTIGATING THE CONTENT VERSUS LANGUAGE DISTINCTION ${ }^{1}$
}

Ewa Clayton

The language issue is a pressing one in tertiary education. Some English L2 university students perceive the language barrier to be a serious hindrance on the path to academic success and similar sentiments are voiced by lecturers and tutors. This research investigates the content vs language dichotomy and - in answering the question whether more emphasis should be put on language skills or on reinforcing subject specific knowledge - it supports the view that the problem appears to be more content related.

Die taalkwessie in tersiêre onderwys is van dringende belang. Party Engelssprekende T2universiteitstudente beskou die taalgrens as 'n ernstige versperring onderweg na akademiese sukses, en soortgelyke standpunte word deur dosente en tutors geopper. Hierdie navorsing ondersoek die tweespalt tussen inhoud en taal en, in die beantwoording van die vraag of taalvaardigheid bo die verwerwing van vakspesifieke kennis beklemtoon moet word of andersom, onderskryf dit die standpunt dat die probleem. waarskynlik veral inhoudverwant is.

\section{INTRODUCTION}

\subsection{STATEMENT OF THE PROBLEM}

The changing demographic profile of the University of the Witwatersrand has led to an increasing number of students from disadvantaged backgrounds. It is expected that the percentage of these students will continue to increase until the diversity of the student population more accurately reflects the ethnic and social diversity of the general population of Gauteng. Statistics of the University of the Witwatersrand indicate (Table 1) that the number of educationally deprived students, in particular black students, has increased markedly in the last 8 years (AISU, University of the Witwatersrand 1996). 
Table 1: Enrolment at the University of the Witwatersrand 1988 - 1995

\begin{tabular}{||l|l|l|l|l|}
\hline Year & White & Black & Total & \% of Black \\
\hline 1988 & 15397 & 2140 & 19255 & 11,1 \\
1989 & 15321 & 2464 & 19675 & 12,5 \\
1990 & 15394 & 2773 & 20282 & 13,7 \\
1991 & 15173 & 3124 & 20518 & 15,2 \\
1992 & 14447 & 3322 & 20081 & 16,5 \\
1993 & 13219 & 3709 & 19395 & 19,1 \\
1994 & 11719 & 4004 & 18239 & 22 \\
1995 & 10867 & 4681 & 18187 & 25,7 \\
\hline
\end{tabular}

(Academic Information System Unit, University of the Witwatersrand, 1996)

The very high rate of failure among these underprepared students is of serious concern. There are a large number of factors contributing to their lack of academic success and consequent exclusion. In many cases, there appears to be a cluster of interconnected causes rather than one specific problem.

Agar (1990) has provided a list of some of the causes of high failure rates. One of them is the students' inadequate command of English, especially for academic purposes. Some of the others are financial problems, workload, and lack of study skills. Insufficient proficiency in English as a cause of failure is a reason given by many lecturers and tutors. Agar (ibid.) lists the language problem as the second most important obstacle to the students' success (after lack of study skills) - as perceived and ranked by the lecturers, across the whole spectrum of subjects. ${ }^{2}$ Many of the students at the University of the Witwatersrand regard lecturers' overemphasis on language proficiency as a major obstacle and express frustration over 'unjustly' marked tests and assignments.

There is strong interest in issues arising from English for academic purposes, which is reflected in the large number of publications worldwide. Cummins and others (Samuda et al. (1989); Richardson and Bender (1991); Hondy et al. (1992)) have attempted to define some of the difficulties. Descriptions, however, focus on a wide range of aspects from something as broad as academic discourse to competent use of specific jargon. Given the different approaches represented and varying learning contexts, the role of language in academic achievement remains difficult to define.

In an academic setting, content knowledge is undoubtedly of primary importance when students are being tested, given the very purpose of their enrolment at the university. Although lecturers may vary in the degree of leniency as far as the quality of the English used is concerned, they seem to apply similar standards in the assessment of newly acquired and applied knowledge. The question which arises is whether lecturers can make a firm distinction between content knowledge and language proficiency. Is it not possible to determine accurately whether the 'fault' lies with content knowledge or inadequate linguistic proficiency? 
While AD has now evolved into an integral component of tertiary education in South Africa, its structure, emphasis and methods of operation vary at different Universities. Therefore, a brief description of the Academic Development Programme (ADP) at the University of the Witwatersrand is required.

This Academic Development Programme has been in existence for 14 years. Initially started as a small, inter-faculty unit, it focused on academic study skills and English language courses. Unsatisfactory feedback caused by the decontextualisation of those skills and the supplementary, non-credit bearing nature of these courses led academic departments and the core Academic Development unit to look for other options and/or further alternatives which would be more in line with the students' expectations and needs. As a result, more emphasis was placed on discipline-specific support, with study and language skill components incorporated into it (Hunter 1989; Agar 1992).

It seemed clear that further modification of the Academic Development Programme was required. Consequently, at Wits University, the steps have been taken to reduce the ADP core group, while expanding subject support and integrating it formally with Faculties and Departments. The function of the central unit will be to do research, as well as training and consultancy.

Years of experience have shown subject support to be most beneficial to students whose strongest need is for discipline-specific assistance. Furthermore, tutors will benefit too. While still technically being faculty based, they will have access to the central ADP unit's expertise in training and the teaching of study skills.

\subsection{LINGUISTICS AS AN ACADEMIC SUBJECT}

The need for subject support is often corroborated by Linguistics students in general who admit to experiencing serious difficulties with the demands of the discipline itself. These include the understanding of concepts, being able to apply them competently, and precision of expression. Language and study skills problems are perceived as being of secondary importance.

Like other sciences, Linguistics aims to be objective, consistent and systematic in its field - the account of language. It relies on data collection to test hypotheses and construct theories. The field of linguistics involves the study of a great range of languages, from 'hard' sciences such as physics, as well as traditionally 'soft' subjects as, for example, literary criticism. It is this breadth of coverage and the resulting requirement of appropriateness of expression and style which students find both fascinating and challenging.

\section{THEORETICAL FRAMEWORK AND HYPOTHESIS}

The theoretical base for the present paper was provided by Cummins's Language Proficiency Framework (1984). This model was a response to misconceptions of language proficiency amd the deleterious consequences for the education of immigrant children. Cummins refutes the 
notion that the learners' control of structures of standard English can be equated with the ability to think logically as fallacious. The fallacy he refutes is that the mastery of conversational skills is a valid index of overall proficiency in the language.

Cummins's model makes a fundamental distinction between conversational and academic aspects of language proficiency.

Drawing on research findings of others as well as his own investigation of the progress of French students in Canada, Cummins (1979/80) made a distinction between appropriate language skills in conversational settings which he calls 'basic interpersonal communicative skills' (BICS), and the mastery of 'cognitive academic language proficiency' (CALP). After further research (Cummins 1984), he developed a more complex description of language proficiency. This dichotomous distinction between BICS ('the manifestation of language proficiency in everyday communicative contexts' p.136) and CALP ('manipulation of language in decontextualised academic situations' p.137) is conceptualised along two continua. The horizontal continuum marks the degree of cognitive involvement demanded of a learner by a specific communicative situation, from 'cognitively undemanding' to 'cognitively demanding' (p.143). In other words, it conceptualises 'developmental aspects of communicative proficiency in terms of the degree of active cognitive involvement in the task or activity' (Cummins and Swain, 1986:154). The model is represented in four quadrants: context embedded and cognitively undemanding; context-embedded and cognitively undemanding; and context reduced and cognitively demanding; context reduced and cognitively undemanding. In the context-embedded situation, the student's language is supported with a range of meaningful and situational cues; feedback helps to clarify the message. In the context-reduced communication, on the other hand, the student can rely only on language itself for the successful interpretation of the message. These two dimensions intersect, yielding four quadrants within which we can locate linguistic activities.

Context-embedded communication
Cognitively undemanding communication

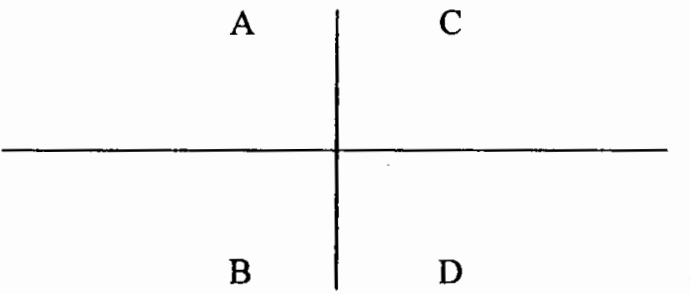

D
Context-reduced communication

Cognitively demanding

communication

Context-reduced activities tend to be more cognitively demanding than context-embedded ones, whereas conversational settings which are more context-embedded, tend to place lower demands on cognitive activities. In the University context, which focuses on the acquisition, application and transferral of knowledge, the linguistic demands of the classroom generally lie in quadrant $\mathrm{D}$ (context-reduced and cognitively demanding). 
Bearing in mind that in conditions of high cognitive demand it is necessary to stretch one's linguistic resources and strategies to the limit in order to achieve one's goals (which sometimes appears to be done at the expense of the content), I decided to contrast the demands close to the context-reduced end of the continuum with those lying towards the context-embedded end.

In determining the degree of cognitive involvement and contextual support it is necessary to consider the influence of both external and internal factors. The external factors have been usefully discussed elsewhere (Agar, 1990; related problems in Hernandez, 1991). Internal ones may be described as referring to the attributes of the individual, such as cognitive ability (however difficult that may be to measure), motivation, and familiarity with the topic. Linguistics as a subject is equally new to both 'traditional' students and those from disadvantaged backgrounds. For example, comprehension of texts may be more or less difficult, depending on objective factors such as syntactic complexity; but the degree of difficulty is also coloured by familiarity with the topic and individual motivation.

If Cummins's theoretical framework is applied - his model to our context - we might discover that the students' CALP skills require attention, whereas the BICS are perfectly acceptable. One might suspect that in a less formal situation, with less stress and decreased emphasis on language and expression, the content (i.e. in this study, knowledge of linguistics) will still surface, albeit somewhat impoverished, with the help of additional coping strategies on the part of the student, as well as feedback from the tutor (sometimes unconscious and unintentional).

Although CALP skills are distinct from content knowledge, they certainly allow a manifestation of such knowledge. The appropriate and competent use of a discipline-specific language presupposes familiarity with the material studied and understanding of the new terminology. Deficient CALP, however, should not be seen as evidence of major ignorance in the subject.

The hypothesis that content knowledge might surface in a more 'student-friendly' setting underlies the tacit assumption concerning the role of an ADP tutor. He or she is not only concerned to foster the academic development of the students he/she works with but acts as a friendly confidante who is aware of more than just gaps in the students' knowledge.

\section{THE STUDY}

The purpose of the study recounted here was to explore whether it is a lack of language proficiency when producing written work in English or their lack of content knowledge that affects the marks of a group of Linguistics $\mathrm{AD}$ students; and to assess to what extent English can be 'blamed' by L2 speakers, when it may be their incomplete coverage of new and often difficult material.

\subsection{DATA COLLECTION}

The data for the present paper was collected during the first semester of 1994. The participants were first-year students of Linguistics. It was intended to be a small-scale study, which would allow the topic to be investigated further at a later stage. Being a linguist myself, I was in the position to assess the students' progress and types of errors. As was noted earlier, Linguistics demands that the language used must be very precise, as in hard sciences. It also demands the 
the use of very specialized jargon. A complicating factor is that some of the words used to describe fundamental concepts (as well as some of the fundamental concepts themselves - to name a few: letter, sound, alphabet, word) are actually known to the students already. However, these terms gain a new meaning and have to be used rigorously. This problem is, of course, not unique to linguistics: for example, in economics, 'price' has a peculiar and different meaning from that commonly understood by non-economists (Ballard and Clanchy 1988).

Unlike other social science departments, the Department of Linguistics at Wits rarely uses essays as a means of testing. Therefore, the samples used for the research were confined to problem-solving, definitions, and competent manipulation of newly acquired specialised terms. These categories highlighted the importance of strict and precise linguistic expression.

The data was collected from mainstream written assignments and tests. The students were ADP students, both L2 students and mother tongue speakers of English. Their participation in ADP tutorials was entirely voluntary, as was their cooperation in the present study. The subdisciplines studied at the time of the research were: introduction to linguistics, comprising animal communication, writing versus speech, neurolinguistics; and a vast and very demanding (and notoriously difficult for first-year students) course in phonetics and phonology. The number of students in the study was 13, out of which 5 were mother tongue speakers of English (L1), and 8 were second language speakers (L2). The division, it needs to be stressed, does not reflect the racial division of the students who were monitored: some L2 speakers were immigrants from Europe and Israel.

\subsection{THE METHOD}

Samples of students' writings were collected from 5 assignments and tests. These were then analysed in such a way that the errors, for which marks were taken off, were noted, just after the assignments had been marked. Normally the lecturer would indicate why marks were subtracted, in order to assist the classification of errors. The errors were then assessed and classified a second time according to the criteria Content (CT) versus Language (LG) errors. 'Content', in the present study, included such varied errors as incomplete answers, irrelevant information given as 'fillers', incorrect guesses, and failure to adhere to instructions whereby, for example, a student provides a monosyllabic answer with no substantiation. Language errors, among others, typically comprised a loss of singular/plural distinctions with the ensuing thematic confusion; and problems with anaphora. In cases where there was any doubt as to the nature of the error, the pertinent lecturer was consulted. The number of errors were computed for each student. Within this number, the mistakes were specified as either CT or LG, as marked on the assignments. Following this process, the students were interviewed by the author, in a conversational setting (quadrant B), and the material was gone over again. In doing so the students' knowledge and intentions were probed, but without the stress or time constraints present in the original test. During this procedure, the students gained awareness of the importance of the precision of expression. 


\section{RESULTS}

The samples of the students' writings were analysed in terms of the errors they contained, i.e. language and/or content errors. The interviews which followed provided a means of testing the classification of the errors or obtaining more insight into the nature of those errors. The results obtained were then computed and tabulated in the table below. The abbreviated headings in the columns denote respectively: student number; student identity; English L1 or L2 speaker; total number of errors; number of content (CT) errors; number of language (LG) errors; LG errors reclassified as CT errors, as a result of probing during interview; remaining genuine LG errors, where content appeared to exist; of the marks deducted, percentage lost as a result of inadequate grasp of language.

Table 2: Analysis of errors

\begin{tabular}{|l|l|l|l|l|l|l|l|l||}
\hline No & ID & $\begin{array}{l}\text { L1/ } \\
\text { L2 }\end{array}$ & $\begin{array}{l}\text { Total } \\
\text { no. of } \\
\text { errors }\end{array}$ & $\begin{array}{l}\text { CT } \\
\text { errors }\end{array}$ & $\begin{array}{l}\text { LG } \\
\text { errors }\end{array}$ & $\begin{array}{l}\text { LG errors } \\
\text { reclassi- } \\
\text { fied as } \\
\text { CT errors }\end{array}$ & $\begin{array}{l}\text { Genuine } \\
\text { LG } \\
\text { errors }\end{array}$ & $\%$ lost \\
\hline 1 & M E & L2 & 9 & 7 & 2 & 1 & 1 & $11,1 \%$ \\
\hline 2 & $\begin{array}{l}\text { SR } \\
\text { M }\end{array}$ & L2 & 16 & 13 & 3 & 2 & 1 & $6,2 \%$ \\
\hline 3 & M M & L2 & 14 & 9 & 5 & 2 & 3 & $21,4 \%$ \\
\hline 4 & H M & L2 & 16 & 12 & 4 & 2 & 2 & $12,5 \%$ \\
\hline 5 & R K & L2 & 3 & 1 & 2 & 1 & 1 & $33,3 \%$ \\
\hline 6 & P M & L2 & 13 & 10 & 3 & 2 & 1 & 7,7 \\
\hline 7 & MM & L2 & 15 & 9 & 6 & 4 & 2 & $13,3 \%$ \\
\hline 8 & T S & L2 & 7 & 7 & - & - & - & - \\
\hline 9 & VdA & L1 & 8 & 4 & 4 & 3 & 1 & $12,5 \%$ \\
\hline 10 & R K & L1 & 12 & 12 & - & - & - & - \\
\hline 11 & J R & L1 & 4 & 4 & - & - & - & - \\
\hline 12 & J M & L1 & 7 & 6 & 1 & 1 & 0 & $14 \%$ \\
\hline 13 & E Y & L1 & 11 & 11 & - & - & - & - \\
\hline
\end{tabular}

The results of the study indicate that language deficiency has in actual fact only a small direct bearing on student performance. In the group studied, language inadequacies account for only a small percentage of the number of errors, while knowledge gaps account for the large majority. 
This study was conducted with a relatively small number of students: a higher number of participants would increase the strength of the results. A further limitation is the restriction of the research to two sections of one discipline. Follow-up studies focusing on other disciplines need to be done.

\section{CONCLUSIONS}

In the attempt to determine whether it is a lack of content knowledge or inadequate command of written academic English which affects the performance of the group studied, the findings of this research suggest that poor written academic language is not a major cause of the students' academic failure. The conclusion to be drawn then appears to be that more emphasis should be placed on integrated teaching, i.e. English taught through the discipline, as recommended by Starfield (1990). The implication for the University seems to be that too much emphasis placed on English as a separate course might not benefit the students greatly on a long term basis. A mastery of technical, subject specific terms and expressions seems, in this study, to account for marks earned rather than general language competence.

No conclusions can be made as to whether poor command of English acts as hindrance to the acquisition of knowledge. Teaching experience and observation, however, suggest that students who have a poor grasp of the language take longer to absorb knowledge, are more easily discouraged, and fail to probe lecturers for further information when concepts are not understood. When these factors are taken into account, the importance of language mastery increases as an explanatory variable with regard to student success or failure. Further research should be done in this area.

It is worth noting that, in an ADP study, Pierce, Starfield et al. (1994) report that $34 \%$ of L2 respondents expressed the view that unless lecturers assess students on their written expression in addition to knowledge assessment, errors would be perpetuated.

This study tentatively challenges the received view that language inadequacies do undermine the academic development of L2 speakers. However, it seems that a poor grasp of key concepts has a far more important role in the failure of such students than is generally realised. Thus bridging curricula which place emphasis on English acquisition qua English acquisition may be a diversion of scarce resources for little return; but closer integration of language skill acquisition into subject teaching in ADP programmes may deliver handsome dividends. 


\section{NOTES}

1. The first version of this paper was presented at the conference of the South African Association for Academic Development, Durban, 30 November - 2 December 1994.

2. It is worth noting that the students' perceptions of the underlying causes of the difficulties they experienced differed from those of their lecturers. The majority of students listed financial problems as those responsible for their lack of academic success.

\section{REFERENCES}

ACADEMIC INFORMATION SYSTEM UNIT (AISU). University of the Witwatersrand, 1996.

AGAR, D. 1990. Non-traditional students: perceptions of problems which influence academic success. Higher Education, 435-454.

AGAR, D. 1992. Evaluating academic support programmes - what have we learnt in the last six years? South African Journal of Education, 12 (2):93-100.

BALLARD, B AND J CLANCHY. 1988. Literacy in the University: An 'anthropological' approach'. In: Taylor, G, B Ballard (Eds). Literacy by degrees. Milton Keynes: Open University Press, 6-23.

CUMMINS, J. 1984. Bilingualism and special education: Issues in assessment and pedagogy, Clevedon, Avon: Multilingual Matters:6.

FRADD, SH AND MJ WEISMANTEL. 1989 Meeting the needs of culturally and linguistically different students. Boston, Toronto, London: A College-Hill Publication, Little, Brown and Company.

HERNANDEZ, JS. 1991. Getting to higher ground: The development of thinking skills for Spanish-speaking students. In McGroarty, ME and CJ Faltis (Eds). Languages in school and society. Berlin, New York: Mouton de Gruyter, 317-334.

HONDY, R, P BEARD AND L MALMBERG. 1992. Second language usage in a tertiary environment. South African Journal of Higher Education, 6 (3):55-57.

HUNTER, AP. 1989. The transforming of learning: the evolution of an Academic Support Programme. South African Journal of Higher Education, 3 (2).

MOLL, I AND L SLONIMSKY. 1989. Towards an understanding of cognition and learning in the academic support context. South African Journal of Higher Education, 3 (1):160-166. 
PEIRCE, B, S STARFIELD et al. 1994. ASP student perceptions of assessment practices at the University of the Witwatersrand. Internal report, University of the Witwatersrand.

RICHARDSON, Jr, RC AND LW BENDER. 1991. Fostering minority access and achievement in higher education. San Francisco, Oxford: Jossey-Bass Publishers.

ROBINSON, JH. 1991. Teaching across academic cultures: Toward an anthropology of ESL. In McGroarty, ME and CJ Faltis (Eds), Languages in school and society, Berlin, New York: Mouton de Gruyter, 151-168.

SAMUDA, RJ, SL KONG et al. 1989. Assessment and placement of minority students. Toronto: Intercultural Social Sciences Publications.

STARFIELD, S. 1990. Contextualising language and study skills. South African Journal of Higher Education, special edition, 142-148. 